\title{
Some critical factors in Local e- Government: the case of Lombardy
}

\author{
Walter Castelnovo, Massimo Simonetta, Antonio Lasi \\ Walter Castelnovo: \\ Università dell'Insubria, via Valleggio, 11, Como, 22100, Italy \\ walter.castelnovo@uninsubria.it \\ Massimo Simonetta: \\ Ancitel Lombardia, via Meucci, 1, Cologno Monzese, 20093, Italy \\ simonetta@ancitel.lombardia.it \\ Antonio Lasi: \\ Lombardia Informatica, via don Minzoni, 24, Milano, 20158, Italy \\ antonio.lasi@lispa.it
}

\begin{abstract}
The implementation of E-Government systems is a complex activity, due especially to the variety of the aspects involved (technological, organizational, normative). The difficulties are even major on the local level, where the task to implement E-Government systems is often entrusted to Small Local Government Organizations (SLGO): for them the management of the innovation can be a problem because of the lack of resources. In this paper, making a reference to a case study in Lombardy Region (Italy), we point out some critical aspects that can arise in the implementation of E-Government systems by SLGOs. The discussion of these elements is based on the data collected through a survey carried out at the end of 2005 on a sample of the 1546 Lombardy municipalities. The survey is based on the use of smart cards for the access to online services of the Local Public Administration. Thanks to some projects carried out in the last few years, in Lombardy already exist all the infrastructural and technological conditions necessary to guarantee a secure access to online services. From this point of view, the critical aspects which arose in the survey and which are discussed in this paper highlight the fact that for SLGOs the problems in the implementation of E-Government systems are not so much technological as actually organizational.
\end{abstract}

\section{Introduction}

Lombardy Region, such as other Italian regions, has defined an E-Government Action Plan of its own [1]. Among the priority projects of this action plan it is especially important the project "Progetto Carta Regionale dei Servizi - Sistema 
Informativo Socio Sanitario" (CRS-SISS: Regional Citizen Card - Healthcare Information System) that has been active since 1999.

Initially, the project was focused on the implementation of healthcare services whose secure access can now be granted to both healthcare professionals and Lombardy citizens by means of the Regional Citizen Card (Carta Regionale dei Servizi, CRS hereafter). However, the final goal of the project is to connect electronically the entire Public Administration and allow citizens to access the complete set of online services.

The CRS card is a smart card that conforms to the international standards, and particularly to the norms that concern the Identification cards. The card can provide identification and authentication functions, as well as electronic signature and payment. [2]

As for December 2005, in the framework of the CRS-SISS project in Lombardy, as many as 8.7 million cards were issued, out of a total of 9.4 million resident citizens. Given its wide diffusion, the CRS card is a tool that could also be applied for accessing the online services of the local Public Administration, fostering the eGovernment development. Actually, for people in Lombardy, the CRS card also acts as National Citizen Card (Carta Nazionale dei Servizi - CNS), i.e. the card providing a secure and authenticated access to the general Public Administration online services. In this respect, analyzing the use of the CRS card by the local municipalities in Lombardy can provide useful information about the general problems to be faced in implementing e-Government solutions.

To this end, in December 2005 a research on a sample of the 1546 Lombardy municipalities was carried out with the aim of acquiring information concerning the level of knowledge of the CRS functions within the Local Government organizations of Lombardy and the main difficulties that could prevent online services from being implemented and used.

In this paper, we present the survey results which point out some critical aspects SLGOs can encounter in the implementation of E-Government systems. On the basis of the discussion of these results, we design an operative model fit to support the implementation of local E-Government systems; in this model are integrated multiple techniques such as information campaigns, training courses, assistance support, promotion incentives, and control policies.

In section 2 we present some data which allows to understand the diffusion of local E-Government systems in Lombardy. In particular, the data concerns the diffusion of E-Government projects financed by Lombardy Region and of projects financed within the E-Government Action Plan of the Italian Government. In section 3 we present the goals and the methodology of the survey. The results and the critical aspects of the survey are discussed in section 4. Finally, section 5 presents the general lines of an intervention model able to support the projects for the implementation of local E-Government systems. 


\section{Local systems of E-Government in Lombardy}

The CRS-SISS project has been initially developed for uses in healthcare applications, whereas the development of E-Government systems in Local Public Administration in Lombardy has been supported especially by two financing forms:

- regional financing for the realization of Sistemi Informativi Sovracomunali di Comunicazione TELematica (SISCOTEL - Inter-organizational Information Systems for Local Government)

- national financing within the national E-Government Action Plan.

\subsection{The regional projects for the activation of SISCOTELs}

The SISCOTEL projects, financed starting from 2001, aim at the implementation of a technological and organizational infrastructure shared within an aggregation of Local Government Organizations for the implementation of associated managements of services.

From the legal and organizational point of view, an associated management of services can take different forms, ranging from the simple delegation to one of the members of the aggregation, to the definition of inter-organizational workflows requiring the cooperation of several organizations for the production and delivery of services to citizens and enterprises. In order to enable the associated management of services within a SISCOTEL, the regional announcements define some technological and organizational conditions which must be fulfilled [3]. Such conditions require:

- to join the virtual private network Lombardia Integrata, which links on equal terms all the member organizations and which allows a safe exchange of information and services between Local Government Organizations of Lombardy; [4]

- to adhere to interoperability and communication standards;

- to structure the application portfolio on the basis of a standard articulation in functional areas and services defined by the Regional Government;

- to realize training projects related to ICT and organizational innovation in all the Local Government Organizations following the programme;

- to activate a Service System Centre which provides to the member municipalities ICT services concerning infrastructures, application, training, contracts and management.

The fulfilment of these conditions determines a technological and organizational integration for the organizations activating a SISCOTEL. From this point of view, an aggregation of municipalities activating a SISCOTEL forms an Integrated System of Local Government [5]. The overall data concerning the financing of the SISCOTELs is shown in Table 1.

Table 1. SISCoTELs financed in the period 2001-2005 [6]

\begin{tabular}{|c|c|c|}
\hline $\begin{array}{l}\text { Year of the financing } \\
\text { announcement }\end{array}$ & $\begin{array}{l}\text { Number of aggregations } \\
\text { financed by each announcement }\end{array}$ & $\begin{array}{l}\text { Total number of municipalities } \\
\text { financed by each announcement }\end{array}$ \\
\hline 2001 & 19 & 191 \\
\hline
\end{tabular}




\begin{tabular}{|c|c|c|}
\hline 2002 & 33 & 396 \\
\hline 2003 & 17 & 157 \\
\hline 2004 & 21 & 191 \\
\hline 2005 & 17 & 166 \\
\hline
\end{tabular}

In the first financing announcements the stress was particularly on the innovation at the back-office level, whereas starting from 2003 the SISCoTEL announcements include explicitly the obligation of implementing online services to citizens and enterprises. In particular, the announcements provide that the financed aggregations must implement at least 3 services to be supplied through the CRS within 3 years from the beginning of the project.

\subsection{E-Government national projects}

The Ministry for Innovation and Technology defined two phases of intervention for the realization of E-Government in Italy. These two phases, through the Ministry's co-financing, have supported innovation projects on a territorial level. The second phase is still being started, while the first phase is coming to its conclusion.

The first phase started in 2002 with an announcement for the co-financing of EGovernment projects. This first announcement was followed by the presentation of 377 projects, whose overall value was 1200 million euros. Out of these 377 projects, 138 have been co-financed with 120 million euros (for an overall value of about 500 million euros).[7]

Out of all the projects which have been financed, 18 involved public administrations of Lombardy. Out of these, 4 were carried out directly by the Lombardy Region, whereas 14 concerned Local Public Administration. Table 2 contains a list of the 14 projects, showing their coordinating administration, the financed amount, and the population covered by the services which were the object of the different projects. Since the projects financed aggregations of local public administrations without any territorial link, table 2 shows also projects covering part of the population of other regions in Italy, even though the coordinating administration is a public administration of Lombardy.

Table 2. E-Government projects involving public administrations of Lombardy [8]

\begin{tabular}{|l|l|l|l|}
\hline Coordinator & Object & Financing & $\begin{array}{l}\text { Covered } \\
\text { population }\end{array}$ \\
\hline $\begin{array}{l}\text { Province of } \\
\text { Brescia }\end{array}$ & Library system of the province of Brescia & 170.000 & 2.232 .540 \\
\hline $\begin{array}{l}\text { Municipality } \\
\text { of Milan }\end{array}$ & $\begin{array}{l}\text { Wireless and mobile access to } \\
\text { administrative processes related to } \\
\text { economic activities }\end{array}$ & 180.000 & 1.285 .000 \\
\hline $\begin{array}{l}\text { Province of } \\
\text { Bergamo }\end{array}$ & $\begin{array}{l}\text { Access to the computerized cartographic } \\
\text { data of the province of Bergamo }\end{array}$ & 40.000 & 974.000 \\
\hline Municipality & Delivery of services to citizens and & 1.430 .000 & 203.596 \\
\hline
\end{tabular}




\begin{tabular}{|c|c|c|c|}
\hline of Como & enterprises through the Web & & \\
\hline $\begin{array}{l}\text { Municipality } \\
\text { of Milan }\end{array}$ & $\begin{array}{l}\text { System for the online management and } \\
\text { payment of taxes and rents }\end{array}$ & 980.000 & 1.686 .495 \\
\hline $\begin{array}{l}\text { Municipality } \\
\text { of Milano }\end{array}$ & $\begin{array}{l}\text { Use of ICTs in order to simplify and foster } \\
\text { the relations both among enterprises and } \\
\text { local Public Administration, and among } \\
\text { different PAL }\end{array}$ & 260.000 & 1.200 .000 \\
\hline $\begin{array}{l}\text { Province of } \\
\text { Lecco }\end{array}$ & $\begin{array}{l}\text { Delivery of services to citizens and } \\
\text { enterprises through the National Citizen } \\
\text { Card }\end{array}$ & 400.000 & 310.000 \\
\hline $\begin{array}{l}\text { Municipality } \\
\text { of } \\
\text { Tavazzano }\end{array}$ & $\begin{array}{l}\text { Realization of a modular and scalable solu- } \\
\text { tion for front-office and e-government } \\
\text { services for citizens and enterprises }\end{array}$ & 680.000 & 357.109 \\
\hline $\begin{array}{l}\text { Municipality } \\
\text { of Bergamo }\end{array}$ & $\begin{array}{l}\text { Implementation of services for citizens and } \\
\text { enterprises mostly on UE level } 4 \text { of } \\
\text { interaction }\end{array}$ & 3.270 .000 & 3.408 .944 \\
\hline $\begin{array}{l}\text { Province of } \\
\text { Milano }\end{array}$ & $\begin{array}{l}\text { Realization of an information system for } \\
\text { employment services (involving } 16 \\
\text { provinces and } 2 \text { regions) }\end{array}$ & 3.210 .000 & 13.000 .000 \\
\hline $\begin{array}{l}\text { Province of } \\
\text { Pavia }\end{array}$ & $\begin{array}{l}\text { Secure mailing among citizens, enterprises } \\
\text { and public offices and interoperability } \\
\text { among the registering systems }\end{array}$ & 610.000 & 497.000 \\
\hline $\begin{array}{l}\text { Municipaliy } \\
\text { of Milano }\end{array}$ & $\begin{array}{l}\text { Management of the relations among } \\
\text { schools, enterprises and Public } \\
\text { Administrations }\end{array}$ & 600.000 & 1.380 .201 \\
\hline $\begin{array}{l}\text { Province of } \\
\text { Milano }\end{array}$ & $\begin{array}{l}\text { E-Procurement system involving also other } \\
\text { regions }\end{array}$ & 100.000 & 5.800 .000 \\
\hline $\begin{array}{l}\text { Municipality } \\
\text { of Desio }\end{array}$ & $\begin{array}{l}\text { Realization of a computerized front office } \\
\text { for the online delivery of services to citizens } \\
\text { and enterprises }\end{array}$ & 200.000 & $3.965,121$ \\
\hline
\end{tabular}

\section{Characteristics of the survey}

The survey on the CRS functions awareness in the municipalities of Lombardy has been jointly run by Lombardia Informatica and by Ancitel Lombardia. Lombardia Informatica is a company that, in behalf of the Lombardy Region, contributes in bringing to fruition electronic systems that enable citizens and companies to access local government and healthcare services. Ancitel Lombardia is the service company of ANCI Lombardia (the association of the municipalities of Lombardy).

The aim of the survey was identifying the critical aspects SLGOs can encounter in the innovation projects through the analysis of the use of the CRS, in order to plan the most appropriate interventions to support them in the implementation of the local E-Government projects.

The information survey was carried out in December 2005 and involved a sample of 30 municipalities, representing the 1546 towns present in Lombardy. The sample selection criteria included: distribution in demographic classes (18 small towns with less than 5000 inhabitants, 7 towns between 5000 and 30,000 inhabitants, and 5 
towns above 30,000 ); coverage of all the 11 counties (at least 2 municipalities per county) and geographical areas of the Lombardy region (mountain, high plain, low plain); differentiated vocation for innovation (measured in number of innovative projects run by the municipalities in the latest years).

The survey included two different approaches: sending out a questionnaire to be filled in and a subsequent interview to operators selected by the municipalities.

The acquired information mainly concerns the following subjects:

1. the organization solutions adopted to fulfil the ICT functions, as structure devoted to manage the implementation of online services and the integration of the CRS card into their provision to citizens and enterprises;

2. the technological and organizational innovation capability, as applied to three financed innovative projects; namely: the realization of SISCoTEL, the projects promoting inter-communal cooperation, and some national e-Government projects;

3. the municipality adhesion to the regional infrastructure system for eGovernment, and specifically to Lombardia Integrata;

4. the degree of awareness and use of the CRS card in the local community. Particularly, the survey focused on the level of knowledge of the CRS functions and the application of the card in the existing or newly designed services;

5. any success or failure factors found out during the process of implementing online services.

All municipalities answered the questions in the questionnaire and willingly cooperated in the interviews. People interviewed were evenly distributed between ICT managers and political members of the municipality government. That allowed the evaluation of the opinion of both operators and decision makers of the Public Administration in Lombardy.

\section{Results of the survey}

The collected data shows a good vocation to the innovation in the sampled municipalities (Table 3). A partial exception concerns the adhesion to the national eGovernment projects. This can however be explained by the specific constraints that those projects implied, especially for small municipalities.

Table 3. Innovation projects in the sampled municipalities

\begin{tabular}{|l|l|l|l|l|}
\hline Project & Involved & Not involved & \multicolumn{2}{|l|}{ Degree of satisfaction } \\
\hline \multirow{3}{*}{ SISCoTEL } & \multirow{2}{*}{$67 \%$} & $33 \%$ & Positive & $54 \%$ \\
\cline { 4 - 5 } & & & Negative & $14 \%$ \\
\cline { 3 - 5 } & & Too early to say & $14 \%$ \\
\cline { 3 - 5 } & & No answer & $18 \%$ \\
\hline $\begin{array}{l}\text { Project promoting } \\
\text { intercommunal } \\
\text { cooperation }\end{array}$ & $54 \%$ & $46 \%$ & Positive & $64 \%$ \\
\cline { 4 - 5 } & & Negative & $12 \%$ \\
\cline { 3 - 5 } & & Too early to say & $12 \%$ \\
\hline
\end{tabular}




\begin{tabular}{|l|l|l|l|l|}
\hline & & & No answer & $12 \%$ \\
\hline \multirow{2}{*}{$\begin{array}{l}\text { National e- } \\
\text { Government projects }\end{array}$} & $30 \%$ & $70 \%$ & Positive & $78 \%$ \\
\hline & & Negative & - \\
\cline { 3 - 5 } & & Too early to say & $11 \%$ \\
\hline & & No answer & $11 \%$ \\
\hline $\begin{array}{l}\text { Adhesion to the } \\
\text { Regional } \\
\text { infrastructure system } \\
\text { (Lombardia Integrata) }\end{array}$ & $87 \%$ & $13 \%$ & Positive & $67 \%$ \\
\hline
\end{tabular}

The data related to the involvement of the sampled municipalities in innovation projects makes particularly meaningful the information about their state of awareness and use of the CRS card (Table 4). In spite of the wide diffusion of the card among the citizens, the number of municipalities already capable of providing services using this authentication tool is absolutely marginal (3\%). This result is not significantly modified by including data concerning projects still in progress and that can potentially lead up to the card application in online services within a reasonable period of time. In fact, $77 \%$ of the municipalities has currently no project in progress related to the implementation of online services using the CRS card.

Table 4. Awareness and use of the CRS card

\begin{tabular}{|l|l|l|}
\hline \multirow{3}{*}{ Level of awareness about the CRS card and its functions } & High & $17 \%$ \\
\cline { 2 - 3 } & Medium & $17 \%$ \\
\cline { 2 - 3 } & Low & $66 \%$ \\
\hline Current state of use of the CRS card & Used & $7 \%$ \\
\cline { 2 - 3 } & Not used & $90 \%$ \\
\cline { 2 - 3 } & No answer & $3 \%$ \\
\hline Project in progress for adopting the CRS card & Project(s) running & $23 \%$ \\
\cline { 2 - 3 } & No project & $77 \%$ \\
\hline
\end{tabular}

Furthermore, in spite of the good involvement in innovation projects, $66 \%$ of the interviewees stated they have little knowledge of the CRS functionalities and the potential benefits related to its applications. This data clearly points out how difficult it is for the municipalities, especially small ones, to launch innovation processes that include the CRS card adoption, even though the card is so widely available among the citizens. Therefore, it becomes essential to find the actions required to encourage and support the small municipalities in their innovation efforts.

To achieve this goal, the research included a qualitative survey that, based on the knowledge and perception of the interviewees, allowed identifying the troubles that could arise during the implementation of online services and the introduction of the CRS card. The interviews highlighted some potential obstacles capable of hindering the diffusion of the card. These obstacles are related to:

- insufficient knowledge of the CRS functionalities;

- contextual factors present in the Public Administration in Italy, and particularly in Lombardy;

- organizational problems 


\subsection{Obstacles related to insufficient knowledge of the tool}

Almost all interviewees emphasised that, notwithstanding the efforts made in the latest years for promoting the diffusion of the CRS card, there is still a lack of knowledge of the tool in both providers and users of the services. The inadequate internal knowledge is perceived as a problem in understanding the potential benefits in using the CRS card and in planning services that can profit of this new tool.

One of the reasons indicated to explain the insufficient knowledge is the poor sharing of information within the organization. If the interviewee is part of the Information System management, he/she claims a medium/good understanding of the tool, whereas there seems to be no awareness about the organizational difficulties related to the implementation of online service using the CRS card. On the contrary, when the interviewee has no specific ICT background, the technical aspects are reported as unclear, while the possible organizational problems are taken into better account.

From this point of view, the collected data confirms the existence of a problem of general character: the difficulty in carrying out innovation projects without the previous creation of a minimum level of shared knowledge within the organization. As a matter of fact, the presence of subcultures within the organization, even without leading to internal conflicts, can anyway slow down the innovation projects. [10]

\subsection{Obstacles related to contextual factors}

Among the general obstacles identified as limiting factors in the diffusion of CRS card applications, the following causes have been reported:

- the long duration of the processes for implementing online services;

- the potential interferences between projects simultaneously dealing with CRS applications;

- the confused situation caused by multiple introductions or announcements of tools providing similar functions as the CRS card.

The implementation process duration has been found to be especially critical when the entire life cycle of an innovation project is taken into account, from design until deployment. The main difficulty reported is that, even when the service is actually implemented, it is not actually available yet, as users may not be able to access it due to insufficient information or missing tools (card, PIN, smart card reader).

It is also clear that, if the services take a long time to be introduced, a problem arises in the communication and relationship with the citizens. It often happens that new services are announced right from the projects' start, thus creating expectations among the citizens. At this point, the long period of time required to put the service into operation may cause the expectations to turn into disappointment and criticism.

Quite a few projects have been in progress for some years in Lombardy to encourage smart card applications for accessing public online services (SISCOTEL projects and national e-Government projects). The variety of projects and initiatives 
has been recognised as a problem since a municipality may risk to be involved in different projects whose application areas overlap. This situation generates real or potential conflicts that can delay or even stop entirely the projects.

Some interviewees pointed out also the potential risks of confusion caused by the availability of tools that, possibly due to poor information, may be considered comparable to the CRS card. Such tools include: the Electronic Identity Card, digital signature tools from various operators, some Smart Cards locally used for testing new services.

Although the problem reported is mainly originated by poor knowledge and communication, a substantial lack of clarity does exist in relation to functions and diffusion of the different tools. This lack of clarity, partially due to an insufficient integration between national and local innovation actions, is considered as a potential constraint, which may prevent CRS-adopting project from being activated.

Many potentially critical elements pointed out in the interviews refer to the necessity of defining a regulation authority capable of coordinating the innovation projects and of controlling their duration and execution. This regulating and coordinating role is particularly necessary in situations in which, due to the lack of resources, an innovation project on the regional level must be carried out through projects funded by different subjects (National, Regional and Local Government). However, the problem of coordinating the funding of E-Government is a general one, as observed in [11].

\subsection{Obstacles connected to the internal organization}

The list of expected problems reported in the interviews about the projects for the implementation of online services also includes:

- organizational difficulties caused by the complexity of the innovation projects management;

- lack of specific skills in the ICT domain, required by the innovation processes;

- deficiency of financial resources to invest in innovation projects.

The sample of municipalities mostly includes small towns, thus representing the actual composition of the urban territory in Lombardy. Although a widespread involvement in innovation initiatives has been measured in all municipalities, it is quite reasonable to expect organizational difficulties to arise in running innovation projects. What the interviews have emphasised is that even the largest municipalities report similar problems.

As far as the small municipalities are concerned, the plans for the CRS card use are part of projects that involve an aggregation of several nearby towns. The organizational problems reported in the interviews are in fact typical of this type of inter-communal cooperation, and similar to the ones found out in previous surveys carried out in Lombardy ([8]). Namely:

- poor scalability, which results in ignoring the differences between small and large towns;

- difficulties in handling the relationships between the different municipalities involved in the common project; 
- allocation of project costs, whenever the projects require, at least partially, financing from the local administrations;

- complications related to norms and/or regulations arising from CRS card applications (e.g.: services requiring the management of personal and sensitive information).

An organizational difficulty, also reported in case of large municipalities, not necessarily involved in inter-communal cooperation, concerns the lack of specific organizational skills within the organization to manage complex project. The problem is clearly related to the CRS project characteristics - cross-sector tasks, high organizational complexity, and medium to long duration - which all require Project Management methods and techniques. These needs result clearly from the interviews, even the ones carried out in medium and large municipalities that, however, are not equipped with specialists to assign to the project management.

The analysed sample confirms a well-known phenomenon in the local Public Administration in Lombardy, as found out in previous surveys ([5]). In spite of the increasing diffusion and availability of ICT in the municipalities, specialist skills for managing the new technology are in general poor or even almost missing in the smaller organizations.

Regarding the specific subject of the analysis, the interview findings show how poor (or missing) specialist skills is a limiting factor for the projects aimed at spreading the use of the CRS card. It is important to note that this problem is not only reported in relation to the need of communicating with the infrastructure specialists of the CRS technical domain, but also for planning, implementing, and managing services that simply use the card.

Nearly all interviewees pointed out, in one way or another, the needs of financial support by the Lombardy Region in terms of:

- direct interventions for providing incentive to the municipalities to test and run services (planning, infrastructure acquisition, training);

- direct or indirect financial support for promoting the use of the CRS card by the citizens (e.g.: contributing for covering the card purchase cost, funding new assisted stations to access online services using the CRS card).

\section{Conclusions}

In general, the most important finding in the analysis of the survey results is the very limited use of the CRS card by the municipalities in Lombardy. This occurs even though the card is, in practise, spread over the entire population and its application would enable the municipalities to profit from the infrastructural services for authentication and security already implemented by the Region.

The CRS card has a key application domain in the healthcare system in Lombardy and the investment for the card distribution can be evaluated in relation to this application. Now, as the tool is available and the investment costs have been 
already covered, its adoption by local Public Administration does not require any further major investment.

Therefore, the CRS card can be a fundamental opportunity for developing eGovernment services in the local Public Administration in Lombardy, one of the most populated and economically important regions in Italy. However, in order for the local Public Administration in Lombardy to adequately profit from this opportunity, the municipalities need to be supported in resolving the difficulties that this survey has highlighted.

The comments received during the survey confirm that the most serious difficulties in running e-Government projects lie in organizational issues more than in technological ones. In this respect, an intervention model only focused on the technological preconditions to enable the municipalities to implement online services would simply appear inadequate.

This aspect is particularly important, as E-Government projects are often almost exclusively considered as technological innovation projects. On the contrary, the collected data clearly points out that the modernization of Local Government needs much more investments in organizational innovation than those made up to now. Consequently, also the incentive policies, from the EU to the local level, should be reoriented from technological innovation to organizational innovation.

The main problems which arose in the survey are schematically summarized in table 5:

Table 5. Main data highlighted by the survey

\begin{tabular}{|l|l|}
\hline \multirow{2}{*}{$\begin{array}{l}\text { General and context-based } \\
\text { obstacles }\end{array}$} & Interferences between different projects \\
\cline { 2 - 2 } & Potential conflicts between CRS and similar tools \\
\hline Insufficient knowledge & Difficulties in recognizing services that can use CRS \\
\cline { 2 - 2 } & Problems in planning new services that can profit of CRS \\
\hline \multirow{2}{*}{$\begin{array}{l}\text { Technological and } \\
\text { organizational problems }\end{array}$} & Troubles in managing innovation processes \\
\cline { 2 - 2 } & Lack of specific ICT skills \\
\cline { 2 - 2 } & Missing financial resources \\
\hline
\end{tabular}

The analysis of the collected data, especially the data resulting from the interviews, clearly points out that for the activation of innovation projects in Local Government it is not enough to give the municipalities the necessary technological tools. As a matter of fact, the municipalities also need to be supported in their innovation processes. The results of the survey carried out in Lombardy point out at least five specific fields which require supporting actions: communication, training, assistance, control, incentives.

In the specific case of the survey on the use of the CRS by the municipalities of Lombardy, the information actions have to encourage the use of the card by spreading the knowledge of its capabilities. On the one hand, more information is required by the Public Administration operators, who have to plan, implement, and manage the services integrating CRS. On the other hand, information campaigns for all citizens should stimulate the use of the card by creating a better understanding of the tool, which, at the moment, is only known for the healthcare applications. 
The goal of the training activities is to improve the operating know-how in CRS applications, thus creating the conditions for implementing new functions and integrating the use of CRS in the municipality's services.

The assistance activities aim at providing effective answers to the possible critical cases encountered in the innovation processes related to the implementation and introduction of CRS-based services.

The control actions should ensure a harmonised and coordinated development of innovation solutions by providing an adequate legal and regulatory framework for the organizations of the system of Local Government.

Finally, the incentive actions are meant to motivate and finance the local administrations in experimenting and introducing innovative solutions that make use of the CRS card.

Without extended plans including communication, training, incentives, and organizational support, the mere distribution of an authentication tool, even though technically adequate, is not sufficient to trigger innovation processes.

The survey carried out on the use of the CRS by the municipalities of Lombardy gives general information about the problems that can arise in the implementation of E-Government on the local level. As a matter of fact, since the adoption of the CRS does not bring with it particular technological problems specifically referable to that tool, the problems pointed out can be considered as typical problems of the innovation processes within SLGOs.

From this point of view, the communication, training, assistance, control and incentive actions described above can be considered as the basis of an integrated intervention model aiming at supporting the processes for the implementation of $\mathrm{E}$ Government on the local level.

\section{Appendix}

The survey was carried out in the period 1-20 December 2005. Firstly the municipalities selected as part of the sample received a questionnaire to be filled in. Subsequently, an appointment was arranged at each municipality; during these meetings the questionnaires were collected and interviews with persons indicated by the municipalities were carried out. The interviews followed the structure of the questionnaire (table 6). At the end of each interview a report was prepared to be subsequently used for the elaboration of the qualitative data of the survey.

Table 6. Structure of the questionnaire

\section{GENERAL DATA}

1a. INTERVIEWED PERSONS

- Manager/member of the council: name, function

- ICT manager (if present): name, function, salary scheme 
1b. IDENTIFICATION OF THE CASE

- Municipality

- Number of inhabitants

- Number of employees

- Organization solutions adopted for the management of ICTs.

\section{PREVIOUS EXPERIENCES OF ICT INNOVATION}

2a. PARTICIPATION IN SISCOTEL

- Identification: Coordinating Authority for the project; Year of adhesion

- State of the project: State of progress of the project; Degree of satisfaction; Positive elements experienced during the project; Critical elements experienced during the project; Any general remarks.

2b. PARTICIPATION IN PROJECTS OF INTERCOMMUNAL COOPERATION

- Identification: Coordinating Authority for the project; Year of adhesion

- State of the project: State of progress of the project; Degree of satisfaction;

Positive elements experienced during the project; Critical elements experienced during the project; Any general remarks.

- Services object of the cooperation that use the CRS.

2c. PARTICIPATION IN NATIONAL E-GOVERNMENT PROJECTS

- Identification: Coordinating Authority for the project; Year of adhesion

- State of the project: State of progress of the project; Degree of satisfaction; Positive elements experienced during the project; Critical elements experienced during the project; Any general remarks.

- Online services object of the project: level of interactivity, authentication tool used.

2d. LOMBARDIA INTEGRATA

- Adhesion to Lombardia Integrata: year of adhesion

- Use of the services implemented on the network

- Degree of satisfaction

- Any general remarks concerning Lombardia Integrata

\section{REGIONAL CITIZEN CARD}

3a. DEGREE OF KNOWLEDGE CONCERNING THE CRS

- Degree of knowledge about the CRS within the organization

- Main information sources concerning the CRS

- Initiatives considered as suited for spreading the knowledge of the CRS

3b. USE OF THE CRS

- Present use of the CRS to supply municipal services:

If yes, please tell if its use is part of a financed project; 


\section{If yes, services delivered through the CRS; \\ If yes, difficulties encountered in the use of the CRS; \\ If yes, success factors in the use of the CRS.}

- Ongoing projects involving the use of the CRS:

If yes, please tell if its use is part of a financed project;

If yes, services for which it has already been planned the use of the CRS;

If yes, predictable difficulties in the use of the CRS (based on past experience in innovation projects)

- If there are no uses, actual or planned, of the CRS, please explain why.

3c. GENERAL EXPECTATIONS CONCERNING THE USE OF CRS

- Services considered as more suitable for the use of the CRS in general terms

- Services (not only online services) of one's own municipality for which the use of the CRS could be useful

3d. SUGGESTIONS/PROPOSALS

- Qualifying factors for the success of the CRS

- Limiting factors for the success of the CRS

- Suggestions aiming at the use of the CRS in the municipality

- General remarks

\section{References}

1. Regione Lombardia, E-Lomb@rdia - all'e-government all'e-governance, Documento strategico 2002-2005 per la diffusione della Società dell'Informazione in Lombardia, online: www.mininnovazione.it/.

2. www.crs.lombardia.it

3. Regione Lombardia, BANDO Misura 2.3 lett. a) - Doc.U.P. - Piano regionale di attivazione dei sistemi informativi di comunicazione telematica degli enti locali SISCOTEL - 2000-2006, online: www.ors.regione.lombardia.it.

4.http:/www.regione.lombardia.it/servlet/ContentServer?pagename=PortaleLombar dia\%2FGenDoc\%2FPL_GenDoc light\&c $=$ GenDoc\&cid $=1040065661144 \&$ dir_gen $=1034250918121 \&$ fronte $=$ off\&ottica $=$ off.

5. W. Castelnovo and M. Simonetta, Organizing E-Gov for Small Local Government Organizations, Proceedings of the 5th European Conference on E-Government, Antwerpen, Belgium, 16-17 June 2005.

6. www.ors.regione,lombardia.it/OSIEG/AreaServiziRete/hpRete.shtml.

7. www.cnipa.gov.it. 
8. Terzo rapporto sull'innovazione digitale in Lombardia - 2005, online: www.cnipa.it.

9. IreR, Sistemi associati negli enti locali lombardi, Istituto Regionale di Ricerca della Lombardia (codice ricerca IReR 2001C033), Milano 2002.

10. E. H. Schein, Three cultures of management: The key to organizational learning, Sloan Management Review, 38, pp. 1, 9-20.

11. OECD, The e-Government Imperative, OECD e-Government Studies, 2003, online: www.oecd.org. 